\title{
Information and entropy theory for the sustainability of coupled human and natural systems
}

\author{
Audrev L. Maver ${ }^{1}$, Richard P. Donovan $^{2}{ }^{2}$ and Christopher W. Pawlowski ${ }^{3}$
}

\begin{abstract}
For coupled human and natural systems (CHANS), sustainability can be defined operationally as a feasible, desirable set of flows (material, currency, information, energy, individuals, etc.) that can be maintained despite internal changes and changes in the environment. Sustainable development can be defined as the process by which CHANS can be moved toward sustainability. Specific indicators that give insight into the structure and behavior of feedbacks in CHANS are of particular interest because they would aid in the sustainable management of these systems through an understanding of the structures that govern system behavior. However, the use of specific feedbacks as monitoring tools is rare, possibly because of uncertainties regarding the nature of their dynamics and the diversity of types of feedbacks encountered in these systems. An information theory perspective may help to rectify this situation, as evidenced by recent research in sustainability science that supports the use of unit-free measures such as Shannon entropy and Fisher information to aggregate disparate indicators. These measures have been used for spatial and temporal datasets to monitor progress toward sustainability targets. Here, we provide a review of information theory and a theoretical framework for studying the dynamics of feedbacks in CHANS. We propose a combination of information-based indices that might productively inform our sustainability goals, particularly when related to key feedbacks in CHANS.
\end{abstract}

Key Words: CHANS; feedbacks; information theory; sustainability

\section{INTRODUCTION}

In 1987, the Bruntland Commission wrote a widely cited definition of sustainable development: "to meet the needs of the present without compromising the ability of future generations to meet their own needs" (World Commission on Environment and Development 1987:43). This definition describes coupled human and natural systems (CHANS) in which a desired level of human use of natural resources and ecosystem services can persist indefinitely (Mayer et al. 2007). Because of the size and complexity of CHANS (also known as human-environment, human-nature, or social-ecological systems; Liu et al. 2007a) at regional and global scales, researchers interested in their management are continuously searching for indicators of the state and trajectory of these systems relative to sustainability targets, e.g., indicators such as a system's resilience to perturbations (Scheffer et al. 2001, Walker et al. 2004, Millennium Ecosystem Assessment 2005, Folke 2006, Zurlini et al. 2006, Mayer et al. 2007, Mayer 2008, Brondizio et al. 2009, Orians and Policansky 2009, Angelstam et al. 2013). Here, we use the definition of an indicator as a measured variable that is used to monitor a dynamic system, usually relative to target values or desirable bounds (Bell and Morse 2008, Mayer 2008).

Many sustainability indicator systems use traditional, disciplinary categories (i.e., ecological, social, economic; Gibson et al. 2005), often in a pressure-state-response (PSR) or similar framework, which focus on state variables such as mean global temperatures or concentration of mercury in water bodies, and known pressures such as carbon dioxide emissions or mercury emissions from power plants (Turner 2000, Carr et al. 2007, Bell and Morse 2008, Levrel et al. 2009, Orians and Policansky 2009, Ness et al. 2010, Meyar-Naimi and Vaez-Zadeh 2012). However, PSR frameworks usually involve several difficulties: (1) the appropriate targets or goals are not necessarily known or agreed upon; (2) equal weighting of ecological, social, and economic indicators might not be warranted (and other weighting systems are not well defended); and (3) these frameworks do not easily allow for feedback-based indicators (Dawson et al. 2010). Although feedbacks are critically important for understanding sustainability in CHANS (Tainter 2000, Turner and Robbins 2008), feedback-based indicators are rare. Even when important system feedbacks can be defined, multiple variables derived from several disciplines might be involved in complex feedback relationships that are difficult to integrate into a single indicator. Indeed, the lack of monitoring of critical feedbacks can enhance their influence on a CHANS through inattention to critical system behaviors or unwarranted reactivity to noncritical ones (Dawson et al. 2010, Biggs et al. 2012). For this reason, characterizing transdisciplinary systems based on thermodynamics, information, and complex systems theory is becoming popular, because these methods can incorporate both feedbacks as indicators and multiple disciplinary emphases without the need to prioritize among them (Mayer 2008, Turner and Robbins 2008).

Information theory provides an interdisciplinary framework for investigating dynamic systems and their behaviors, including nonlinear behaviors and relationships; understanding these characteristics is necessary for CHANS research and management (Liu et al. 2007a,b). For example, whereas ecologybased disciplines focus on feedbacks generated by environmental processes and sociology-based disciplines focus on the implications that these feedbacks have on human societies (Turner and Robbins 2008), an information-based approach regards all feedbacks and their impacts on system components as neutral with respect to human viewpoints; feedbacks are integrated into the information measure according to their influence on the system, without explicit disciplinary or other prejudice. The human viewpoint is integrated when system trajectories are considered relative to sustainability goals.

Here, we briefly review feedbacks as they have been observed in CHANS and then discuss the use of information theory to study 
system entropy and Fisher information. We then begin a conversation on how information-based indices, along with network analysis, might provide a new approach for integrating signals from the behavior of system feedbacks into the sustainable management of CHANS. This conceptual paper is intended to highlight the general approach of applying Fisher information and entropy theory to CHANS, where CHANS are described via network theory as a dynamic system of components with a structure of various feedback types.

\section{FEEDBACKS IN COUPLED HUMAN AND NATURAL SYSTEMS}

Although the existence of feedbacks in CHANS and their importance to sustainable management are readily acknowledged, it is not uncommon for feedbacks to receive simply passing treatment, even in models meant for managing feedbacks between natural and human subsystems (Schlüter et al. 2012). Occasionally, specific feedbacks are identified with enough clarity to allow for their use as indicators. Turner et al. (2007) and Liu et al. (2007a) provide reviews of many different case studies of CHANS, and both reviews explicitly describe feedbacks within these systems such that indicators could be generated. Others have identified human-environment feedbacks in aquatic systems (Chen et al. 2009, Roy et al. 2010, Schlüter and Herrfahrdt-Pähle 2011), agricultural systems (Hartter and Boston 2007, Lawrence et al. 2007, Koch et al. 2008, Walsh et al. 2008), international trade (Kissinger and Rees 2010), and regulatory systems meant to manage these systems for sustainability (Horan et al. 2011, Biggs et al. 2012, Rounsevell et al. 2012). Huber-Sannwald et al. (2006) and Davidson et al. (2012) focus explicitly on these feedbacks when developing a model and framework, respectively; however, the influence of human activities on the drivers in the system (another type of feedback) are not identified. In the social collapse literature, feedbacks are occasionally described as systems of cascading feedbacks, or "cascading devolutionary feedbacks", that destabilize CHANS and greatly increase the odds of collapse or failure, with possible reorganization if "buffering feedbacks" are strong enough (Butzer and Endfield 2012, Dunning et al. 2012). Trophic cascades are an ecological example of the same phenomenon (Dawson et al. 2010). Missing from this body of literature on CHANS is an approach with which to examine many specific feedbacks in a system holistically such that the overall behavior of a system can provide an indication that one or more system feedbacks are changing in intensity, scale, and/or behavior. A methodology that could be used across many types of dynamic systems, allowing for comparative analyses, would be even more desirable. We argue that information theory-based approaches might be one way to conduct such system-level analyses for CHANS.

\section{INFORMATION AND ENTROPY}

Information theory is an interdisciplinary area of research that focuses on understanding the nature of communication in its broadest sense. Information is quantifiable as the amount of order or organization provided by a message (Haken 2006); entropy is one measure.

The Shannon entropy of a finite sample of a random variable $X$ is given by: $-\sum_{i} P\left(x_{i}\right) \log \left(P\left(x_{i}\right)\right)=E[-\log (P(X))]=E[I(X)]$

In equation [1], the negative of the logarithm of the probability mass function $P$ is a measure of the (self-) information (I), i.e., the more certain an event, the less information its occurrence adds to our understanding of the underlying process. Thus, the Shannon entropy is the expected or average value of (self-) information in a random variable.

Shannon was originally concerned with communication of messages from a sender to a receiver through a transmission line with variable amounts of noise or uncertainty. The effect of noise on the reliability of the message transmission can be minimized by either increasing the redundancy of information in the message (making it less likely that important bits would be lost, but slowing down the message), or increasing the power (i.e., energy) used to send the message, combating the noise directly. The theory has been used to characterize general behavior of complex systems. For example, ecologists use the Shannon-Wiener index (often referred to as Shannon diversity) to measure biodiversity (Magurran 2004); the more species there are (in more equal numbers) in a community, the harder it is to predict to which species the next sampled individual might belong. Whereas physicists might prefer their systems to have low (thermodynamic) entropy, ecosystems that have relatively high Shannon entropy (greater diversity) may lead to more stable ecosystems (although consensus on this issue has not been achieved; McCann 2000, Ives and Carpenter 2007, MacDougall et al. 2013). In a system with many species that can perform similar roles or fit into similar guilds, the loss of one species will usually result in its place being taken by one or more remaining species (Biggs et al. 2012). In this case, high Shannon entropy actually signals high redundancy in function, therefore conveying resilience to the ecosystem (MacDougall et al. 2013).

Entropy has its roots in thermodynamics, capturing degradation in the quality of energy, or gradients more generally, in physical processes (Gatenby and Frieden 2013, Michel 2013). Entropy can also be useful in characterizing emergent ecosystem behavior, including mechanisms for feedback in CHANS. For example, the principle of maximum entropy (MaxEnt) can be used to derive analytic relationships that describe the probability distributions of metrics associated with ecosystem function such as the spatial distribution, abundance, and energetics observed in undisturbed natural systems (Harte 2011). The concept of maximum entropy production (MEP) builds on MaxEnt and postulates that system states or configurations that maximize entropy production (degradation of gradients) are selected because they are compatible with a greater number of environments (Dewar and Maritan 2011). In addition, the generalized forces associated with physical processes (diffusion, heat and energy flows, etc.) that accompany entropy gradients (Ruth 2011) can provide pathways through which feedback occurs in well-connected systems (Gatenby and Frieden 2013).

However, in terms of sustainability, the system that is most efficient at degrading gradients under one environment does not necessarily remain the same following changes in environmental gradients. Ulanowicz et al. (2009) suggest that it is a diversity of 
processes (a diversity of redundant energy pathways, for example) that makes it possible for a system to persist. Such diversity is necessary to allow a system to adjust its organization in the face of change. Fowler (2008) went further and argued that Shannon diversity can be an indicator of sustainability, where management decisions can be judged on whether they will result in the loss of Shannon diversity. Ebeling and Volkenstein (1990) argued that living organisms are information-processing agents, and through evolution and self-organizing processes, energy is used to produce and exchange information (Cabezas and Fath 2002, Kumar and Ruddell 2010). This information production comes at the expense of increased entropy in the larger system (Michel 2013).

Another information theoretic measure of order is Fisher information. Fisher information is the second moment of the partial derivative of the logarithm of the probability density function, and is given by:

$$
\begin{aligned}
F I(\theta) & =E\left[\left(\frac{\partial}{\partial \theta} \log _{2} P(X ; \theta)\right)^{2} \mid \theta\right] \\
& =\int\left(\frac{\partial}{\partial \theta} \log _{2} P(x ; \theta)\right)^{2} P(x ; \theta) d x \\
& =\int\left(\frac{\partial}{\partial \theta} P(x ; \theta)\right)^{2} / P(x ; \theta) d x
\end{aligned}
$$

In the above, $E[\cdot \mid \Theta]$ is the conditional expectation over values of $X$ given $\Theta$, and $P$ is the probability density function of the random variable conditioned on the parameter $\Theta$, equivalent to the likelihood function for $\Theta$. Fisher information is a measure of the "sharpness" of the logarithm of the likelihood function at the maximum likelihood estimate.

Cabezas and Fath (2002) adapted Fisher information to measure temporal order in an ecosystem. While Shannon entropy is a global measure that decreases with the predictability of a system, Fisher information under their formulation is a local measure that increases with system predictability as given by its time-series history. High Fisher information indicates a system residing in a stable state, and low Fisher information a system residing in a transient state. Internal negative feedbacks developed by the system itself serve to maintain the system in the stable state. Therefore, these negative feedbacks may be interpreted as increasing the order or information of the system as a whole (Mayer et al. 2007) and as relays sending information about the system to itself (James 2000, Kumar and Ruddell 2010, Gatenby and Frieden 2013). Zellner et al. (2008) used Fisher information in a model simulating urban sprawl to identify those policies that result in more ordered growth patterns that also reduce energy consumption and pollution emissions. More broadly, Fisher information has been used to monitor the resilience of numerous complex systems in economics, medicine, biology, astrophysics, and sociology (Frieden and Gatenby 2007). In terms of the resilience and sustainability of CHANS, Fisher information and Shannon entropy characterize the predictability or consistency associated with sustainability, and the diversity necessary for sustainability (Cabezas and Fath 2002, Mayer et al. 2007).

As systems develop they often become more complex, governed by increasing numbers of feedback loops. This complexity represents a growth in information storage (Jørgensen 2006), and feedbacks provide information to the system on its position and trajectory (James 2000, Gleick 2011, Michel 2013). In social systems, connections and feedbacks allow for the flow of information among individuals and groups and for the development and trust that creates and sustains social capital, a critical component of resilience in CHANS (Brondizio et al. 2009, Biggs et al. 2012). Therefore, system feedbacks affect both predictability and diversity, and structural changes in system feedbacks can result in changes in predictability and diversity. The reverse can occur as well; changes in predictability or diversity can lead to changes in feedback structure. For example, a loss of diversity due to overharvesting of herbivorous fish can lead to structural changes in system feedbacks in coral reef ecosystems (Hoey and Bellwood 2011).

To see how information theoretical concepts can connect entropic changes to feedbacks, consider the relationship between entropy production and constraint forces associated with thermo-physical processes in material systems. For these systems, feedbacks are functionally associated with the forces that accompany changes in entropy and that bind (i.e., constrain) a system in a (relatively) low entropic configuration. For example, a mass of sand consisting of many individual identical grains (same number of molecules, voids, volume, shape, mass, etc.) arranged into a geometric configuration has significantly higher entropy (relative to potential disturbances) than the pane of glass that results from an energetic reduction in the entropy of that sand. These constraint forces (in this case molecular forces such as ionic, covalent, or van der Waals) hold the molecules in a preferred configuration that has significantly lower entropy relative to the collection of loose sand because of the high probability of locating a particular molecule at a particular location. These same constraint forces also enable the glass to have useful properties such as transparency while transferring load (such as wind or acoustic pressure) to supporting structures. The system of constraint forces connecting the response of individual and collections of molecules also provides a framework through which information can be fed back to the system regarding its current and future state. For example, the constraints that give the glass the necessary stiffness to resist load also provide pathways for feedbacks such as resonance that can result from high-pitched sounds that shatter the glass. In contrast, the mass of unbound and undifferentiated sand particles will readily absorb or dissipate essentially all acoustic frequencies.

Just as for the sand pile or the glass, CHANS are subject to "constraint forces" in terms of their feedback structure and similarly receive information through this structure. Consider a CHANS in which negative interactions are of the first order and decrease entropy to produce a gradient in the entropy that characterizes the state change of the system. The negative entropy gradient between these states will produce a feedback system that increases its "stiffness" in the sense that relatively small perturbations of one element in a two element system produce large changes in the second element. After a sufficient number of 
interactions, an identifiable feedback structure emerges that could be characterized as, for example, either ductile (relatively high entropy with an associated higher capacity to absorb energy) or brittle (relatively low entropy and prone to sudden catastrophic failure). In this view, a disturbance could pass through the system with relatively little impact or it could rearrange feedbacks, create new (formerly forbidden) feedbacks, or strengthen previously weak positive feedbacks if the disturbance has a particular characteristic frequency. Much as information theory helped to measure the signal-to-noise ratio in telephone transmissions, indices based on information theory might offer an approach to measure how disturbance events that arrive into a CHANS intensify, weaken, and/or rearrange feedbacks. Such indices might be tuned to variations in feedback strength as well as reconfigurations of elements in feedback relationships in the same way that the number and size of cracks, and the crack tip velocity (indicators of changes in the strength and configuration of constraint forces) in brittle materials indicate an imminent dramatic system state change. Although the link between these constraint forces and entropy production are well known for thermo-physical systems (Ruth 2011, Verlinde 2011), less is known about their relationship in CHANS. The example described here is intentionally simplified to illustrate the role of entropy gradients in a thermo-physical system and their relationship to CHANS.

\section{A FRAMEWORK FOR FEEDBACKS AS INDICATORS IN COUPLED HUMAN AND NATURAL SYSTEMS}

Up to this point, we have been referring to feedbacks generally. However, we advocate for the recognition of a rich taxonomy of feedbacks. The path that a given system has taken in the past and will take into the future is the result of a set of feedbacks that have been acting (positive and negative), and have not been acting (missing or forbidden), along with their intensity and scale. If there are no fundamental changes to the system and the historical data set is representative of a given regime of behavior, a prediction in the next time step based on an accurate model should have high confidence. As changes in feedbacks occur (in terms of their structure and/or relative intensity) in response to disturbances, new behaviors become possible, the regime of behavior changes, and the correspondence between prediction and system behavior is reduced. This leads to more indeterminacy and less information. This loss of information can occur with no change in entropy if, for example, there are no changes in the structure of the feedbacks, but changes in their intensity. For this reason, both measures (Fisher information and entropy) and a clear understanding of the types of feedbacks operating in the system are necessary. Feedback structures and their influence on system behavior are a major focus of network theory; however, in the interest of brevity, we only discuss a portion of this theoretical background that is most relevant to information theory and CHANS. For a deeper discussion of network theory as it relates to CHANS, we refer interested readers to Patten (1991), Fath and Patten (1998), Bondavalli and Ulanowicz (1999), and Fath (2007).

\section{Positive and negative feedbacks}

In complex ecosystems, the two most common types of interactions are antagonistic (such as competition or predation) and mutualistic (such as pollination). At the population level, these interactions constitute feedbacks; the herbivory of deer on tree seedlings is a negative feedback. Each interaction allows individuals to exchange information (e.g., the threat of being eaten), and at the population level, the number of interactions provides systemic information on the abundance of each population. Generally speaking, negative feedbacks stabilize systems, whereas positive feedbacks destabilize them (Veraart et al. 2012). Occasionally destabilizing systems may be beneficial, such as when restoring degraded systems (Chapin et al. 1996, Twidwell et al. 2013). While discussing the multiple causes of societal declines in the Middle East, Butzer (2012:3635) stated, "the complexity of the social-ecological interface is as much about inter-relationships as it is about the identification of stressors." He emphasized "buffering feedbacks" (negative) that lead to high resilience of the systems and stabilization vs. "cascading feedbacks" (positive) that lead to low resilience, instability, and initial breakdown.

Bascompte (2010) explains that when both positive and negative interactions are considered simultaneously, an understanding of the behavior of the entire system becomes possible. For example, Thébault and Fontaine (2010) compared stability properties of model systems under different network architectures. Trophic networks dominated by negative trophic interactions such as herbivory typically evolved a compartmentalized (or modular) structure in which sets of predators and their prey rarely interacted with other sets. Mutualistic networks dominated by positive interactions such as pollination developed a nested structure in which many species were connected through interactions with other species. The systems dominated by negative feedbacks lost persistence and resilience (where persistence was the proportion of species remaining, and resilience was the speed of return to equilibrium) when connectedness and diversity increased, and vice versa for systems dominated by positive feedbacks. If we generalize this work to any complex system, including a CHANS, this suggests that a system with an abundance of positive feedbacks will be highly connected, with a lot of information flows in many directions. In this situation, the Shannon entropy of the system would be relatively high. If instead the system has a lot of negative feedbacks, the system will have compartmentalized information flows with lower entropy.

The extension of these concepts to CHANS can be facilitated through an equivalence between information theoretical entropy and entropy of thermo-physical systems, and reference to some of the fundamental thermo-physical thermodynamic results in material science previously described. For example, Thébault and Fontaine (2010) characterize alterations to network architecture as a result of the dynamics of interactions through indices such as diversity, connectedness, nestedness, and modularity. These indices naturally admit to characterization in terms of entropy. For example, consider systems for which interactions significantly reduce the diversity of an ecosystem (e.g., the establishment of an invasive species). This reduction in diversity can result in a stiff system that is prone to state shifts when subjected to relatively small energetic perturbations. Changes in indices such as connectedness, nestedness, and modularity can be similarly characterized relative to the feedback networks that accompany entropy gradients associated with these state changes. For example, cascading feedbacks that lead to failures can be 
contained by modularity (moderate connectivity) in the system (Ash and Newth 2007, Galstyan and Cohen 2007). Whereas a moderate level of connectivity confers higher resilience in many systems, too much connectivity tends to reduce resilience but increase recovery speed because disturbances can sweep quickly through the system. This perspective may also have implications relative to the work of May (1972), who suggested that there are stability limits relative to the strength of interactions and web connectance.

\section{Missing and forbidden feedbacks}

The lack of a feedback between system components can be just as influential as positive or negative feedbacks to system resilience and sustainability. Olesen et al. (2011) discussed the importance of missing links (interactions that are so rare that we do not have the opportunity to observe them), and forbidden links (interactions that cannot occur) in mutualistic systems. They propose several different reasons for why a certain interaction between two species might not occur, including "spatio-temporal uncoupling" when two species do not overlap in time or in space so they cannot directly exchange information. Brondizio et al. (2009) stated that an increase in "random connectivity" (that is, new connections that are not developed evolutionarily within a system) might increase the risk of catastrophic behaviors in CHANS. These random connections and associated constraint forces would provide a pathway that can enable feedbacks that previously were missing or forbidden, and therefore, work to destabilize the system, altering existing structures and hence the behavioral signals transmitted to other parts of the system. If this results in a decrease in modularity accompanied by an increase in connections, for example, an increase in forbidden feedbacks would increase the entropy and decrease the information of the system. This is generally what Rees (2006) and Young et al. (2006) have argued with respect to globalization processes.

\section{Intensity of feedbacks}

Changes in feedback structure as well as changes in the degree or intensity of existing feedbacks can affect system resilience (Biggs et al. 2012). Feedbacks represent relationships between system elements and as such are nonlinearly associated with the constraints that drive behavior. While structural changes in system feedbacks change the universe of possible system behaviors, under a given feedback structure, there can be a diversity of system behaviors resulting from changes in feedback intensity as well. Sustainability indices based on information theory should tell us something about these changes. For example, several indicators of critical transitions have been proposed based on the phenomenon of critical slowing down near a fold bifurcation (Carpenter and Brock 2006, Dakos et al. 2008, Guttal and Jayaprakash 2008, Scheffer et al. 2009, Lenton et al. 2012, although see Hastings and Wyshem 2010), and indicate that this behavior might be due to the weakening of negative feedbacks (and relative strengthening of positive ones). However, Scheffer et al. (2009) note that critical thresholds and regime changes can result from other types of bifurcations and thus have associations with different kinds of feedback responses. Information theoretical analytic tools such as those previously described can provide insight that can disambiguate these system behaviors. For example, during these slowing phases, Fisher information may temporarily increase as the system visits fewer states over time, but then will sharply decrease once the system is rapidly transitioning to a new state (Mayer et al. 2007).

\section{Scale of feedbacks in time and space}

Feedbacks and interactions among human and environmental system components are likely to have characteristic time periods and spatial extents that lend themselves to whole system monitoring (Zurlini et al. 2006). For example, fast-paced variables often react to more gradual changes in variables acting at larger scales or over longer time periods (Biggs et al. 2012, Walker et al. 2012). Strengthening the negative (or stabilizing) feedbacks changes the system's natural frequency, thereby mitigating some of the reactivity of the system to larger-scale drivers and lowering the risk of collapse. In CHANS, feedbacks between human and environmental components are common and dynamic. Some of these feedbacks (such as the growing emissions of greenhouse gases and the resulting climate change) have considerable time lags, which can significantly complicate their study and management (Liu et al. 2007a). Furthermore, increased connectedness at large scales through international trade, migration, and globalization might make formerly loose or indirect feedbacks more intense and forbidden feedbacks possible (Young et al. 2006, Liu et al. 2007a, Brondizio et al. 2009).

The question then becomes: How can we reliably characterize these processes? Looking through the lens of information theory, changes in entropy or information at particular scales might be an indicator of a gain or loss in overall resilience in systems. Both of these measures are scale dependent, and combining data from different scales without normalization or other compensation techniques might reduce their utility (Mayer et al. 2006). For example, May (1972) built upon the work of Gardner and Ashby (1970) to suggest that for large, complex systems (systems with many elements and high connectance), stability is possible up to a critical level of connectance beyond which instability is assured. This comports with the notion that constraint networks emerge to bind system structure after a sufficient number of entropyreducing interactions. May (1972) also provided evidence of the connection between emergence of structure and entropic reduction by showing that large systems are significantly more likely to be stable when local microstructures, which are associated with reduced entropy, are present. Others have built upon these concepts to suggest that these microstructures "...act as glue keeping the whole network together" (Bascompte 2009:417).

\section{INFORMATION, ENTROPY, AND FEEDBACKS}

Thus far, we have offered a review of how feedbacks have been treated in CHANS research and have provided an information theory-based taxonomy of feedbacks that can provide a more formal structure to their treatment. To apply information and entropy for sustainable systems management, feedbacks must be identified, data must be gathered (or models developed), and indices such as Fisher information and Shannon diversity must be developed to provide relevant information on the organization and behavior of these systems.

Identifying feedbacks in systems or, more generally, couplings between system elements are important tasks toward understanding sustainability in CHANS. This understanding must be developed at multiple scales across multiple dimensions (local to global; ecological, social, and economic). This is no small endeavor. One way to do this is to use the methodology of nonlinear dynamic systems suggested by Sugihara et al. (2012). Their test for coupling between variables is based on a measure of how well the historical record of one variable can predict the 
state of another using time delay embedding. This approach to identifying causal relationships between variables is applicable to systems coupled through deterministic dynamics. In contrast, Granger causality (GC; Granger 1969), which is based on predictability between time-series variables, assumes these are not coupled through a dynamical system. Transfer entropy (Schreiber 2000) offers another approach to determining feedback relationships. It measures the amount of information (reduction in uncertainty) that knowledge of one variable provides about another. Like GC, it assumes that information is not embedded in the variable in question through system dynamics and is equivalent to GC under certain assumptions (Barnett et al. 2009). Kumar and Ruddell (2010) use transfer entropy to identify feedbacks between vegetation and climate components, using observations from a network of Fluxnet monitoring towers across North America. They used Shannon entropy in a matrix of joint and conditional probabilities to identify feedbacks and measure their intensity (or "coupling strength") between vegetation and climate variables at each of the towers. Ecosystems at the colder and drier sites exhibited tighter coupling, responding more quickly to changes in temperature (colder sites) or precipitation (drier sites).

Kumar and Ruddell's (2010) results inspired two hypotheses that demonstrate how information theoretic indices can provide insight to variable interactions based on the specifics of a system such as scale effects. First, systems with greater large-scale variability adapt through more intense and immediate feedbacks at smaller scales, which increases information within the system; in response, information should increase as these feedbacks increase in strength and number. Second, feedbacks that have the most influence in the system display "moderated variability", or fluctuate less than less influential feedbacks; this can be measured using Shannon entropy (Kumar and Ruddell 2010). This balance between high information lending stability and moderate entropy providing resilience suggests that a sustainable state is indicated by stable but not necessarily extreme values of information measures for a collection of system feedbacks (Gatenby and Frieden 2013). To study missing and forbidden feedbacks, simulations or long-term monitoring in areas with recovering vegetation after a disturbance could illustrate the restoration of feedbacks and accompanying change in information and entropy indices as these systems rebuild. Likewise, these indices could be used to compare systems into which a forbidden link such as an invasive species has been (un)successfully integrated.

Entropy and information can also play a role in understanding another important component of sustainability in CHANS: understanding how systems adapt or reconfigure themselves in response to change. Whereas it appears that thermodynamic considerations indicate that systems maximizing entropy production are favored, the system that arises will not necessarily be compatible with sustainability. An understanding of system vulnerability or robustness to change would be necessary, for example, some form of measure of brittleness or ductility of feedbacks. The roles that entropy and information have to play in this understanding are still to be determined, but given the complexity of feedback characteristics and behaviors, measuring their influence on CHANS trajectories toward sustainability goals requires a holistic approach, one that information theory can provide.
Responses to this article can be read online at: http://www.ecologyandsociety.org/issues/responses. $\mathrm{php} / 6626$

\section{LITERATURE CITED}

Angelstam, P., J.-M. Roberge, R. Axelsson, M. Elbakidze, K.-O. Bergman, A. Dahlberg, E. Degerman, S. Eggers, P.-A. Esseen, J. Hjältén, T. Johansson, J. Müller, H. Paltto, T. Snäll, I. Soloviy, and J. Törnblom. 2013. Evidence-based knowledge versus negotiated indicators for assessment of ecological sustainability: the Swedish Forest Stewardship Council Standard as a case study. Ambio 42(2):229-240. http://dx.doi.org/10.1007/s13280-012-0377$\underline{\mathrm{Z}}$

Ash, J., and D. Newth. 2007. Optimizing complex networks for resilience against cascading failure. Physica $A$ - Statistical Mechanics and Its Applications 380:673-683. http://dx.doi. org/10.1016/j.physa.2006.12.058

Barnett, L., A. B. Barrett, and A. K. Seth. 2009. Granger causality and transfer entropy are equivalent for Gaussian variables. Physical Review Letters 103:238701. http://dx.doi.org/10.1103/ PhysRevLett.103.238701

Bascompte, J. 2009. Disentangling the web of life. Science 325:416-419. http://dx.doi.org/10.1126/science.1170749

Bascompte, J. 2010. Structure and dynamics of ecological networks. Science 329:765-766. http://dx.doi.org/10.1126/ science. 1194255

Bell, S., and S. Morse. 2008. Sustainability indicators: measuring the immeasurable? Second edition. Routledge, New York, New York, USA.

Biggs, R., M. Schlüter, D. Biggs, E. L. Bohensky, S. BurnSilver, G. Cundill, V. Dakos, T. M. Daw, L. S. Evans, K. Kotschy, A. M. Leitch, C. Meek, A. Quinlan, C. Raudsepp-Hearne, M. D. Robards, M. L. Schoon, L. Schultz, and P. C. West. 2012. Toward principles for enhancing the resilience of ecosystem services. Annual Review of Environment and Resources 37:421-448. http:// dx.doi.org/10.1146/annurev-environ-051211-123836

Bondavalli, C., and R. E. Ulanowicz. 1999. Unexpected effects of predators upon their prey: the case of the American alligator. Ecosystems 2(1):49-63. http://dx.doi.org/10.1007/s100219900057

Brondizio, E. S., E. Ostrom, and O. R. Young. 2009. Connectivity and the governance of multilevel social-ecological systems: the role of social capital. Annual Review of Environment and Resources 34:253-278. http://dx.doi.org/10.1146/annurev.environ.020708.100707

Butzer, K. W. 2012. Collapse, environment, and society. Proceedings of the National Academy of Sciences 109 (10):3632-3639. http://dx.doi.org/10.1073/pnas.1114845109

Butzer, K. W., and G. H. Endfield. 2012. Critical perspectives on historical collapse. Proceedings of the National Academy of Sciences 109(10):3628-3631. http://dx.doi.org/10.1073/pnas.1114772109

Cabezas, H., and B. D. Fath. 2002. Towards a theory of sustainable systems. Fluid Phase Equilibria 194-197:3-14. http:// dx.doi.org/10.1016/S0378-3812(01)00677-X 
Carpenter, S. R., and W. A. Brock. 2006. Rising variance: a leading indicator of ecological transition. Ecology Letters 9(3):311-318. http://dx.doi.org/10.1111/j.1461-0248.2005.00877.x

Carr, E. R., P. M. Wingard, S. C. Yorty, M. C. Thompson, N. K. Jensen, and J. Roberson. 2007. Applying DPSIR to sustainable development. International Journal of Sustainable Development and World Ecology 14(6):543-555. http://dx.doi.org/10.1080/135$\underline{04500709469753}$

Chapin, F. S. III, M. S. Torn, and M. Tateno. 1996. Principles of ecosystem sustainability. American Naturalist 148(6):1016-1037. http://dx.doi.org/10.1086/285969

Chen, Y., E. G. Irwin, and C. Jayaprakash. 2009. Dynamic modeling of environmental amenity-driven migration with ecological feedbacks. Ecological Economics 68(10):2498-2510. http://dx.doi.org/10.1016/j.ecolecon.2009.01.012

Dakos, V., M. Scheffer, E. H. van Nes, V. Brovkin, V. Petoukhov, and H. Held. 2008. Slowing down as an early warning signal for abrupt climate change. Proceedings of the National Academy of Sciences 105(38):14308-14312. http://dx.doi.org/10.1073/pnas.0802430105

Davidson, E. A., A. C. de Araújo, P. Artaxo, J. K. Balch, I. F. Brown, M. M. C. Bustamante, M. T. Coe, R. S. DeFries, M. Keller, M. Longo, J. W. Munger, W. Schroeder, B. S. Soares-Filho, C. M. Souza Jr., and S. C. Wofsy. 2012. The Amazon basin in transition. Nature 481:321-328. http://dx.doi.org/10.1038/nature10717

Dawson, T. P., M. D. A. Rounsevell, T. Kluvánková-Oravská, V. Chobotová, and A. Stirling. 2010. Dynamic properties of complex adaptive systems: implications for the sustainability of service provision. Biodiversity and Conservation 19(10):2843-2853. http://dx.doi.org/10.1007/s10531-010-9892-z

Dewar, R. C., and A. Maritan. 2011. The second law, maximum entropy production and Liouville's theorem. arXiv arXiv:1107.1088

Dunning, N. P., T. P. Beach, and S. Luzzadder-Beach. 2012. Kax and kol: collapse and resilience in lowland Maya civilization. Proceedings of the National Academy of Sciences 109 (10):3652-3657. http://dx.doi.org/10.1073/pnas.1114838109

Ebeling, W., and M. V. Volkenstein. 1990. Entropy and the evolution of biological information. Physica A: Statistical Mechanics and Its Applications 163(1):398-402. http://dx.doi. org/10.1016/0378-4371(90)90347-U

Fath, B. D. 2007. Network mutualism: positive community-level relations in ecosystems. Ecological Modelling 208(1):56-67. http:// dx.doi.org/10.1016/j.ecolmodel.2007.04.021

Fath, B. D., and B. C. Patten. 1998. Network synergism: emergence of positive relations in ecological systems. Ecological Modelling 107(2-3):127-143. http://dx.doi.org/10.1016/S0304-3800 (97)00213-5

Folke, C. 2006. Resilience: the emergence of a perspective for social-ecological systems analyses. Global Environmental Change 16(3):253-267. http://dx.doi.org/10.1016/j.gloenvcha.2006.04.002

Fowler, C. W. 2008. Maximizing biodiversity, information and sustainability. Biodiversity and Conservation 17(4):841-855. http:// dx.doi.org/10.1007/s10531-008-9327-2
Frieden, B. R., and R. A. Gatenby, editors. 2007. Exploratory data analysis using Fisher information. Springer-Verlag, London, UK. http://dx.doi.org/10.1007/978-1-84628-777-0

Galstyan, A., and P. Cohen. 2007. Cascading dynamics in modular networks. Physical Review E 75:036109. http://dx.doi. org/10.1103/PhysRevE.75.036109

Gardner, M. R., and W. R. Ashby. 1970. Connectance of large dynamic (cybernetic) systems: critical values for stability. Nature 228:784. http://dx.doi.org/10.1038/228784a0

Gatenby, R. A., and B. R. Frieden. 2013. The critical roles of information and nonequilibrium thermodynamics in evolution of living systems. Bulletin of Mathematical Biology 75(4):589-601. http://dx.doi.org/10.1007/s11538-013-9821-X

Gibson, R. B., S. Hassan, S. Holtz, J. Tansey, and G. Whitelaw. 2005. Sustainability assessment: criteria and processes. Earthscan, London, UK.

Gleick, J. 2011. The information: a history, a theory, a flood. HarperCollins, London, UK.

Granger, C. W. J. 1969. Investigating causal relations by econometric models and cross-spectral methods. Econometrica 37(3):424-438. http://dx.doi.org/10.2307/1912791

Guttal, V., and C. Jayaprakash. 2008. Changing skewness: an early warning signal of regime shifts in ecosystems. Ecology Letters 11 (5):450-460. http://dx.doi.org/10.1111/j.1461-0248.2008.01160.x

Haken, H. 2006. Information and self-organization: a macroscopic approach to complex systems. Third edition. Springer, Berlin, Germany.

Harte, J. 2011. Maximum entropy and ecology: a theory of abundance, distribution, and energetics. Oxford University Press, Oxford, UK. http://dx.doi.org/10.1093/acprof:oso/97801995934$\underline{15.001 .0001}$

Hartter, J., and K. Boston. 2007. An integrated approach to modeling resource utilization for rural communities in developing countries. Journal of Environmental Management 85(1):78-92. http://dx.doi.org/10.1016/j.jenvman.2006.08.003

Hastings, A., and D. B. Wysham. 2010. Regime shifts in ecological systems can occur with no warning. Ecology Letters 13 (4):464-472. http://dx.doi.org/10.1111/j.1461-0248.2010.01439.x

Hoey, A. S., and D. R. Bellwood. 2011. Suppression of herbivory by macroalgal density: a critical feedback on coral reefs? Ecology Letters 14(3):267-273. http://dx.doi.org/10.1111/j.1461-0248.2010.01581. $\underline{\mathrm{x}}$

Horan, R. D., E. P. Fenichel, K. L. S. Drury, and D. M. Lodge. 2011. Managing ecological thresholds in coupled environmentalhuman systems. Proceedings of the National Academy of Sciences 108(18):7333-7338. http://dx.doi.org/10.1073/pnas. 1005431108

Huber-Sannwald, E., F. T. Maestre, J. E. Herrick, and J. F. Reynolds. 2006. Ecohydrological feedbacks and linkages associated with land degradation: a case study from Mexico. Hydrological Processes 20(15):3395-3411. http://dx.doi.org/10.1002/ hyp. 6337 
Ives, A. R., and S. R. Carpenter. 2007. Stability and diversity of ecosystems. Science 317:58-62. http://dx.doi.org/10.1126/science.1133258

James, M. R. 2000. Non-linear control systems. Pages 249-288 in T. R. J. Bossomaier and D. G. Green, editors. Complex systems. Cambridge University Press, Cambridge, UK. http://dx.doi. org/10.1017/CBO9780511758744.007

Jørgensen, S. E. 2006. Application of holistic thermodynamic indicators. Ecological Indicators 6(1):24-29. http://dx.doi. org/10.1016/j.ecolind.2005.08.003

Kissinger, M., and W. E. Rees. 2010. Importing terrestrial biocapacity: the U.S. case and global implications. Land Use Policy 27(2):589-599. http://dx.doi.org/10.1016/j.landusepol.2009.07.014

Koch, J., R. Schaldach, and M. Köchy. 2008. Modeling the impacts of grazing land management on land-use change for the Jordan River region. Global and Planetary Change 64 (3-4):177-187. http://dx.doi.org/10.1016/j.gloplacha.2008.09.005

Kumar, P., and B. L. Ruddell. 2010. Information driven ecohydrologic self-organization. Entropy 12(10):2085-2096. http://dx.doi.org/10.3390/e12102085

Lawrence, D., P. D’Odorico, L. Deikmann, M. DeLonge, R. Das, and J. Eaton. 2007. Ecological feedbacks following deforestation create the potential for a catastrophic ecosystem shift in tropical dry forest. Proceedings of the National Academy of Sciences 104 (52):20696-20701. http://dx.doi.org/10.1073/pnas.0705005104

Lenton, T. M., V. N. Livina, V. Dakos, E. H. van Nes, and M. Scheffer. 2012. Early warning of climate tipping points from critical slowing down: comparing methods to improve robustness. Philosophical Transactions of the Royal Society A 370:1185-1204. http://dx.doi.org/10.1098/rsta.2011.0304

Levrel, H., C. Kerbiriou, D. Couvet, and J. Weber. 2009. OECD pressure-state-response indicators for managing biodiversity: a realistic perspective for a French biosphere reserve. Biodiversity and Conservation 18(7):1719-1732. http://dx.doi.org/10.1007/ s10531-008-9507-0

Liu, J., T. Dietz, S. R. Carpenter, M. Alberti, C. Folke, E. Moran, A. N. Pell, P. Deadman, T. Kratz, J. Lubchenco, E. Ostrom, Z. Ouyang, W. Provencher, C. L. Redman, S. H. Scheider, and W. W. Taylor. 2007a. Complexity of coupled human and natural systems. Science 317:1513-1516. http://dx.doi.org/10.1126/ science. 1144004

Liu, J., T. Dietz, S. R. Carpenter, C. Folke, M. Alberti, C. L. Redman, S. H. Schneider, E. Ostrom, A. N. Pell, J. Lubchenco, W. W. Taylor, Z. Ouyang, P. Deadman, T. Kratz, and W. Provencher. 2007b. Coupled human and natural systems. Ambio 36(8):639-649. http://dx.doi.org/10.1579/0044-7447(2007)36[639: CHANS]2.0.CO;2

MacDougall, A. S., K. S. McCann, G. Gellner, and R. Turkington. 2013. Diversity loss with persistent human disturbance increases vulnerability to ecosystem collapse. Nature 494:86-89. http://dx.doi.org/10.1038/nature11869

Magurran, A. E. 2004. Measuring biological diversity. WileyBlackwell, Malden, Massachusetts, USA.
May, R. M. 1972. Will a large complex system be stable? Nature 238:413-414. http://dx.doi.org/10.1038/238413a0

Mayer, A. L. 2008. Strengths and weaknesses of common sustainability indices for multidimensional systems. Environment International 34(2):277-291. http://dx.doi.org/10.1016/j.envint.2007.09.004

Mayer, A. L., C. W. Pawlowski, and H. Cabezas. 2006. Fisher information and dynamic regime changes in ecological systems. Ecological Modelling 195(1-2):72-82. http://dx.doi.org/10.1016/j. ecolmodel.2005.11.011

Mayer, A. L., C. W. Pawlowski, B. D. Fath, and H. Cabezas. 2007. Applications of Fisher information to sustainable environmental management. Pages 217-244 in B. R. Frieden and R. A. Gatenby, editors. Exploratory data analysis using Fisher information. Springer-Verlag, London, UK. http://dx.doi.org/10.1007/978-1-$\underline{84628-777-0 \quad 7}$

McCann, K. S. 2000. The diversity-stability debate. Nature 405:228-233. http://dx.doi.org/10.1038/35012234

Meyar-Naimi, H., and S. Vaez-Zadeh. 2012. Developing a DSRHNS policy making framework for electric energy systems. Energy Policy 42:616-627. http://dx.doi.org/10.1016/j.enpol.2011.12.034

Michel, D. 2013. Life is a self-organizing machine driven by the informational cycle of Brillouin. Origins of Life and Evolution of Biospheres 43(2):137-150. http://dx.doi.org/10.1007/s11084-013-9329-2

Millennium Ecosystem Assessment. 2005. Ecosystems and human well-being: current state and trends, volume 1. Island Press, Washington, D.C., USA. [online] URL: http://www.unep.org/ maweb/en/Condition.Aspx.

Ness, B., S. Anderberg, and L. Olsson. 2010. Structuring problems in sustainability science: the multi-level DPSIR framework. Geoforum 41(3):479-488. http://dx.doi.org/10.1016/j.geoforum.2009.12.005

Olesen, J. M., J. Bascompte, Y. L. Dupont, H. Elberling, C. Rasmussen, and P. Jordano. 2011. Missing and forbidden links in mutualistic networks. Proceedings of the Royal Society B 278:725-732. http://dx.doi.org/10.1098/rspb.2010.1371

Orians, G. H., and D. Policansky. 2009. Scientific bases of macroenvironmental indicators. Annual Review of Environment and Resources 34:375-404. http://dx.doi.org/10.1146/annurev. environ.020608.151439

Patten, B. C. 1991. Network ecology: indirect determination of the life-environment relationship in ecosystems. Pages 288-351 in M. Higashi and T. P. Burns, editors. Theoretical ecosystem ecology: the network perspective. Cambridge University Press, London, UK.

Rees, W. E. 2006. Globalization, trade and migration: undermining sustainability. Ecological Economics 59(2):220-225. http://dx.doi.org/10.1016/j.ecolecon.2005.12.021

Rounsevell, M. D. A., D. T. Robinson, and D. Murray-Rust. 2012. From actors to agents in socio-ecological systems models. Philosophical Transactions of the Royal Society B 367 (1586):259-269.

Roy, E. D., J. F. Martin, E. G. Irwin, J. D. Conroy, and D. A. Culver. 2010. Transient social-ecological stability: the effects of 
invasive species and ecosystem restoration on nutrient management compromise in Lake Erie. Ecology and Society 15 (1): 20. [online] URL: http://www.ecologyandsociety.org/vol15/ iss $1 / \operatorname{art} 20 /$.

Ruth, M. 2011. Entropy, economics, and policy. Pages 402-422 in R. B. Bakshi, T. G. Gutowski, and D. P. Sekulic, editors. Thermodynamics and the destruction of resources. Cambridge University Press, Cambridge, UK. http://dx.doi.org/10.1017/ $\underline{\text { CBO9780511976049.020 }}$

Scheffer, M., J. Bascompte, W. A. Brock, V. Brovkin, S. R. Carpenter, V. Dakos, H. Held, E. H. van Nes, M. Rietkerk, and G. Sugihara. 2009. Early-warning signals for critical transitions. Nature 461:53-59. http://dx.doi.org/10.1038/nature08227

Scheffer, M., S. Carpenter, J. Foley, C. Folke, and B. Walker. 2001. Catastrophic shifts in ecosystems. Nature 413:591-596. http://dx. doi.org/10.1038/35098000

Schlüter, M., and E. Herrfahrdt-Pähle. 2011. Exploring resilience and transformability of a river basin in the face of socioeconomic and ecological crisis: an example from the Amudarya River basin, Central Asia. Ecology and Society 16(1): 32. [online] URL: http:// www.ecologyandsociety.org/vol16/iss1/art32/.

Schlüter, M., R. R. J. Mcallister, R. Arlinghaus, N. Bunnefeld, K. Eisenack, F. Hölker, E. J. Milner-Gulland, B. Müller, E. Nicholson, M. Quaas, and M. Stöven. 2012. New horizons for managing the environment: a review of coupled social-ecological systems modeling. Natural Resource Modeling 25(1):219-272. http://dx.doi.org/10.1111/j.1939-7445.2011.00108.x

Schreiber, T. 2000. Measuring information transfer. Physical Review Letters 85:461. http://dx.doi.org/10.1103/PhysRevLett.85.461

Sugihara, G., R. May, H. Ye, C. Hsieh, E. Deyle, M. Fogarty, and S. Munch. 2012. Detecting causality in complex ecosystems. Science 338:496-500. http://dx.doi.org/10.1126/science.1227079

Tainter, J. A. 2000. Problem solving: complexity, history, sustainability. Population and Environment 22(1):3-41. http://dx. doi.org/10.1023/A:1006632214612

Thébault, E., and C. Fontaine. 2010. Stability of ecological communities and the architecture of mutualistic and trophic networks. Science 329:853-856. http://dx.doi.org/10.1126/ science. 1188321

Turner, B. L. II, E. F. Lambin, and A. Reenberg. 2007. The emergence of land change science for global environmental change and sustainability. Proceedings of the National Academy of Sciences 104(52):20666-20671. http://dx.doi.org/10.1073/ pnas.0704119104

Turner, B. L. II, and P. Robbins. 2008. Land-change science and political ecology: similarities, differences, and implications for sustainability science. Annual Review of Environment and Resources 33:295-316. http://dx.doi.org/10.1146/annurev. environ.33.022207.104943

Turner, R. K. 2000. Integrating natural and socio-economic science in coastal management. Journal of Marine Systems 25 (3-4):447-460. http://dx.doi.org/10.1016/S0924-7963(00)00033-6
Twidwell, D., S. D. Fuhlendorf, C. A. Taylor Jr., and W. E. Rogers 2013. Refining thresholds in coupled fire-vegetation models to improve management of encroaching woody plants in grasslands. Journal of Applied Ecology 50(3):603-613. http://dx.doi. org/10.1111/1365-2664.12063

Ulanowicz, R. E., S. J. Goerner, B. Lietaer, and R. Gomez. 2009. Quantifying sustainability: resilience, efficiency and the return of information theory. Ecological Complexity 6(1):27-36. http://dx. doi.org/10.1016/j.ecocom.2008.10.005

Veraart, A. J., E. J. Faassen, V. Dakos, E. H. van Nes, M. Lürling, and M. Scheffer. 2012. Recovery rates reflect distance to a tipping point in a living system. Nature 481:357-359. http://dx.doi. org/10.1038/nature10723

Verlinde, E. 2011. On the origin of gravity and the laws of Newton. Journal of High Energy Physics 2011(4):029. http://dx.doi. org/10.1007/JHEP04(2011)029

Walker, B. H., S. R. Carpenter, J. Rockstrom, A. S. Crépin, and G. D. Peterson. 2012. Drivers, "slow" variables, "fast" variables, shocks, and resilience. Ecology and Society 17(3): 30. [online] URL: http://www.ecologyandsociety.org/vol17/iss3/art30/.

Walker, B., C. S. Holling, S. R. Carpenter, and A. Kinzig. 2004. Resilience, adaptability and transformability in social-ecological systems. Ecology and Society 9(2): 5. [online] URL: http://www. ecologyandsociety.org/vo19/iss2/art5/.

Walsh, S. J., J. P. Messina, C. F. Mena, G. P. Malanson, and P. H. Page. 2008. Complexity theory, spatial simulation models, and land use dynamics in the northern Ecuadorian Amazon. Geoforum 39(2):867-878. http://dx.doi.org/10.1016/j.geoforum.2007.02.011

World Commission on Environment and Development. 1987. Report of the World Commission on Environment and Development: our common future. Oxford University Press, Oxford, UK. [online] URL: http://www.un-documents.net/wcedocf.htm.

Young, O. R., F. Berkhout, G. C. Gallopin, M. A. Janssen, E. Ostrom, and S. van der Leeuw. 2006. The globalization of socioecological systems: an agenda for scientific research. Global Environmental Change 16(3):304-316. http://dx.doi.org/10.1016/ j.gloenvcha.2006.03.004

Zellner, M. L., T. L. Theis, A. T. Karunanithi, A. S. Garmestani, and H. Cabezas. 2008. A new framework for urban sustainability assessments: linking complexity, information and policy. Computers, Environment and Urban Systems 32(6):474-488. http:// dx.doi.org/10.1016/j.compenvurbsys.2008.08.003

Zurlini, G., K. Riitters, N. Zaccarelli, I. Petrosillo, K. B. Jones, and L. Rossi. 2006. Disturbance patterns in a socio-ecological system at multiple scales. Ecological Complexity 3(2):119-128. http://dx.doi.org/10.1016/j.ecocom.2005.11.002 